\title{
DƯ ÁN CDIO THỰC TẾ CHO CHUYÊN NGÀNH CÔNG NGHỆ KỸ THUẬT Ô TÔ TRONG NĂM THỨ 4
}

\author{
Chu Thành Khải ${ }^{(*)}$, Lê Minh Phụng ${ }^{(*)}$ \\ (*) Thạc sĩ. Đại học Công nghệ Đồng Nai. Email: chuthanhkhai@dntu.edu.vn. \\ DOI: $10.37550 /$ tdmu.CFR/2021.01.115
}

\section{Tóm tắt}

Tại Truò̀ng Đại học Công nghệ Đồng Nai, trong chuơng trình đào tạo kĩ su chuyên ngành công nghẹ kỹ thuật ô tô, các sinh viên sẽ được đào tạo lý thuyết tại truò̀ng và đi đào tạo thực tế tại doanh nghiệp vào năm thư 3 hoạc năm thứ 4. Trong nghiên cưu này, chúng tôi xây dụng dụ án cho sinh viên tham dụ cuộc thi nghiên cứu cải tiến động co thi cuộc thi xe tiết kiệm nhiên liệu. Để đáp ứng được, sinh viên cần phải trang bị các kiến thức về: Nhiệt động lưc học, diều khiển và mô phỏng các hệ thống động lực học, diện tư và hệ thống thủy lục. Công việc trên dư án được thực hiện theo nhóm tù 8 đến 10 sinh viên và sẽ hố trợ về lý thuyết chung được giảng dạy trong các khóa học, đồng thời sẽ cung cấp cho sinh viên các kỹ năng làm việc nhóm, làm việc trên dụ án và xây dựng hệ thống. Kêt quả nghiên cúu chưng minh rằng sinh viên có thể học tốt thông qua hoạt động tích cực và thử nghiệm. Hơn nũa, sinh viên có thể phân tích và kiến nghị trên kết quả thu được.

Từ khóa: công nghệ kỹ thuật ô tô, học theo dụ án, nhiệt động lục học, tiết kiệm nhiên liệu

\section{1. Đặt vấn đề}

Sau đây là mô tả một số yếu tố chính trong việc triển khai một dự án thực tế trong năm học thứ 4 tại Khoa Công nghệ tại Đại học Công nghệ Đồng Nai [1]. Chủ đề là Năng lượng và Thiết kế Hệ thống. Nội dung được sắp xếp dựa trên những kỹ năng mà một kỹ sư phải có trong lĩnh vực công nghệ ô tô. Các yếu tố quan trọng được thực hiện trong dự án là:

- Kết quả:

Kết quả học tập cá nhân: Dự án tập trung đặc biệt vào giải quyết vấn đề, thử nghiệm và khám phá kiến thức, tư duy hệ thống và tư duy sáng tạo dựa trên các vấn đề thực tế.

Kết quả học tập giữa các cá nhân: Dự án tập trung vào tương tác cá nhân và nhóm, các công việc được thực hiện theo nhóm 4 - 6 học sinh [2].

Kỹ năng xây dựng sản phẩm và hệ thống: Hầu hết các dự án được thực hiện với sự hợp tác của các công ty, doanh nghiệp [3]. 
- Chương trình tích hợp: Chương trình bao gồm kinh nghiệm học tập để đạt được các kỹ năng cá nhân, giữa các cá nhân và xây dựng sản phẩm và hệ thống được tích hợp với học lý thuyết liên quan [1].

- Học tập tích cực: Hoạt động dạy và học dựa trên phương pháp học tập thực nghiệm tích cực.

Trong suốt quá trình thiết kế khóa học dự án, chúng tôi đã nhận thức được rằng sinh viên trong phạm vi tối đa có thể phải làm việc theo cùng một cách trong công việc dự án như họ sẽ làm khi họ tốt nghiệp cử nhân kỹ thuật.

\section{Phương pháp triển khai dự án}

Để sinh viên tham gia các cuộc thi, đầu tiên sinh viên phải nắm được các quy định về luật thi của ban tổ chức. Cuộc thi Lái xe sinh thái - Tiết kiệm nhiên liệu Honda nhằm nâng cao ý thức tiết kiệm nhiên liệu và bảo vệ môi trường, đặc biệt là trong thế hệ trẻ. Bằng niềm vui sáng tạo và hoạt động làm việc nhóm, cuộc thi mang tới một sân chơi bổ ích và năng động cho các kỹ sư tương lai thỏa sức sáng tạo.

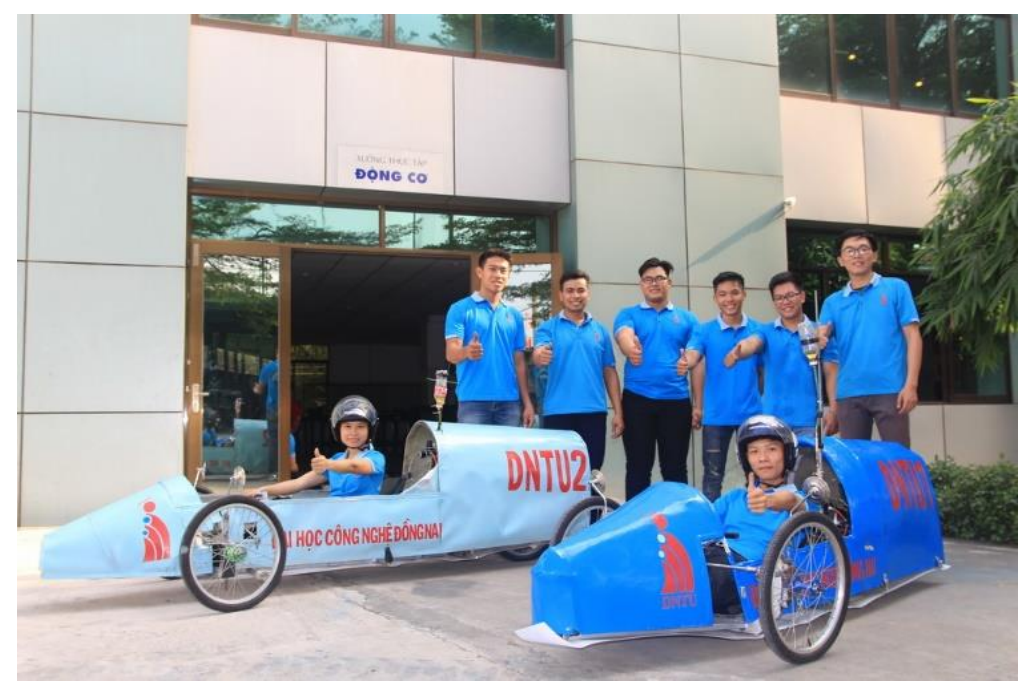

Hình 1. Sinh viên chuyên ngành ô tô chuẩn bị tham dụ cuộc thi

Luật thi đấu: Cuộc thi Lái xe sinh thái - Tiết kiệm nhiên liệu Honda là cuộc thi trong đó người tham gia sẽ ứng dụng các ý tưởng và công nghệ độc đáo để chế tạo ra phương tiện sử dụng động cơ 4 kỳ của Honda đi được quãng đường xa nhất chỉ với 1 lít xăng.

- Tốc độ chạy: tốc độ trung bình tối thiểu $25 \mathrm{~km} / \mathrm{h}$.

- Quãng đường và Thời gian chạy

- Hạng mục: Xe tự chế

- Số vòng 8 vòng

- Số $\mathrm{km} \sim 9.5 \mathrm{~km}$

- Thời gian 22 phút 24 giây

- Lượng nhiên liệu tiêu hao được tính theo công thức: Lượng nhiên liệu tiêu hao = Khối lượng ban đầu - Khối lượng sau khi về đích 
- Công thức tính toán mức tiêu hao nhiên liệu: Mức tiêu hao nhiên liệu $(\mathrm{km} / \mathrm{l})=$ Quãng đường chạy $\div$ (Lượng nhiên liệu tiêu hao $\div$ tỷ trọng nhiên liệu)

Dựa vào luật chơi, sinh viên sẽ phải có kế hoạch trang bị kiến thức cần thiết để thực hiện dự án. Sau đó, sinh viên sẽ được giảng viên trang bị các kiến thức theo kế hoạch sinh viên đã đăng kí. Sinh viên tự sáng tạo, đưa ý tưởng mình vào bản thiết kế, mô phỏng. Và giai đoạn tiếp theo là chế tạo mô hình và nghiệm thu, chạy thử, thi đấu [4]. Đây cũng là giá trị cốt lõi của phương pháp học theo dự án của CDIO.

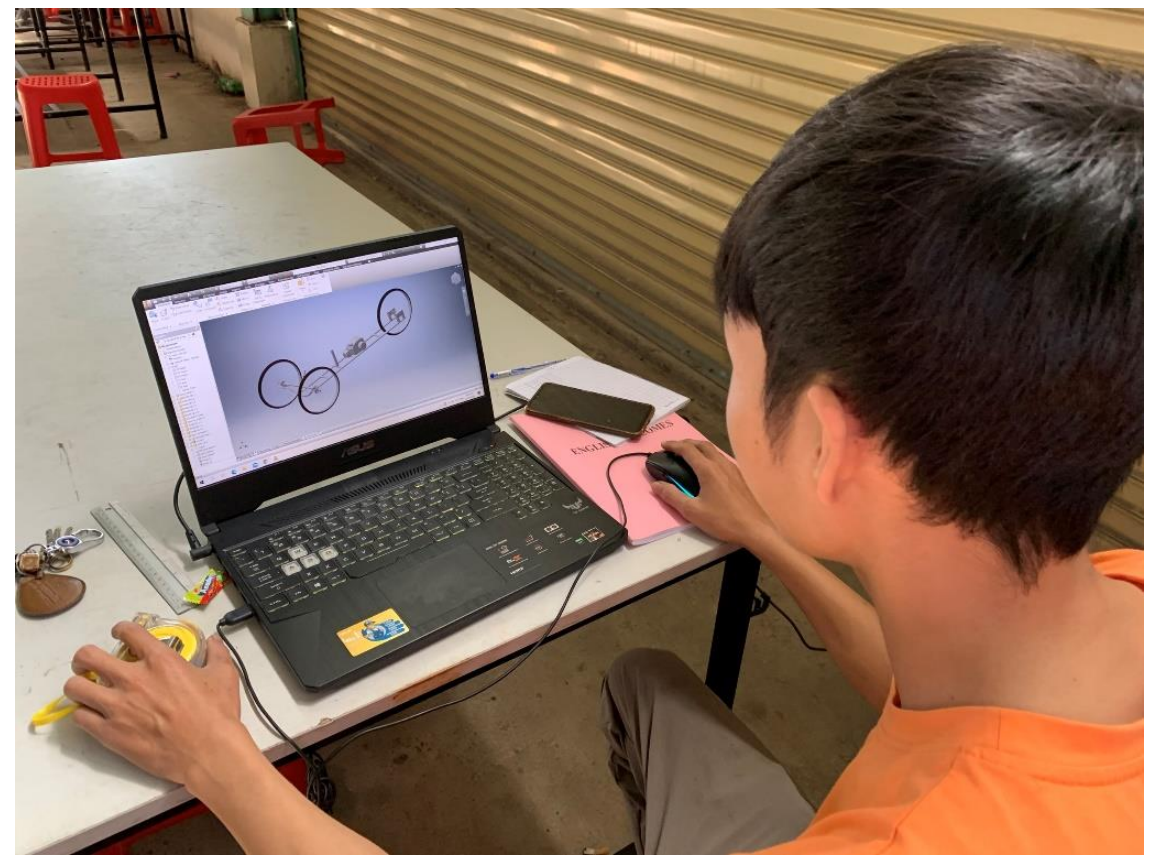

Hinh 2. Sinh viên thiết kế chế tạo khung của xe

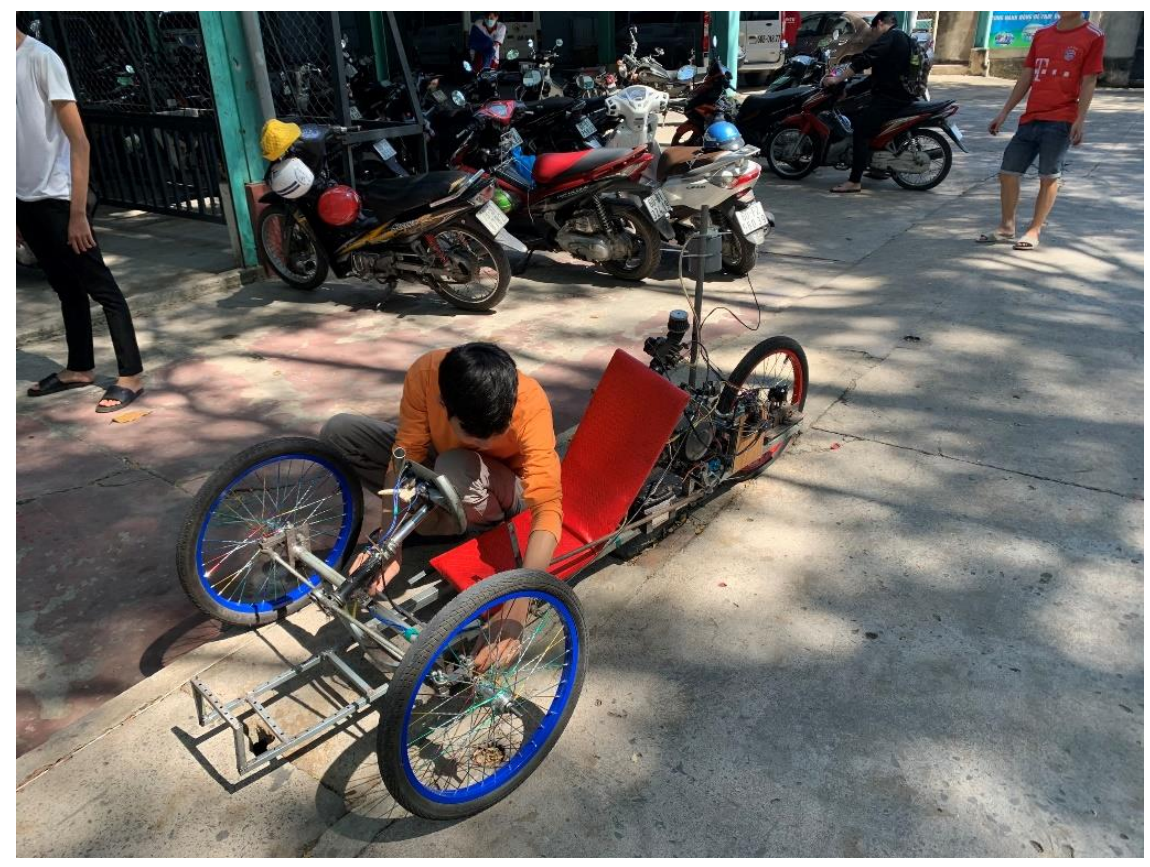

Hình 3. Sinh viên gia công hệ thống lái và hệ thống truyền động 


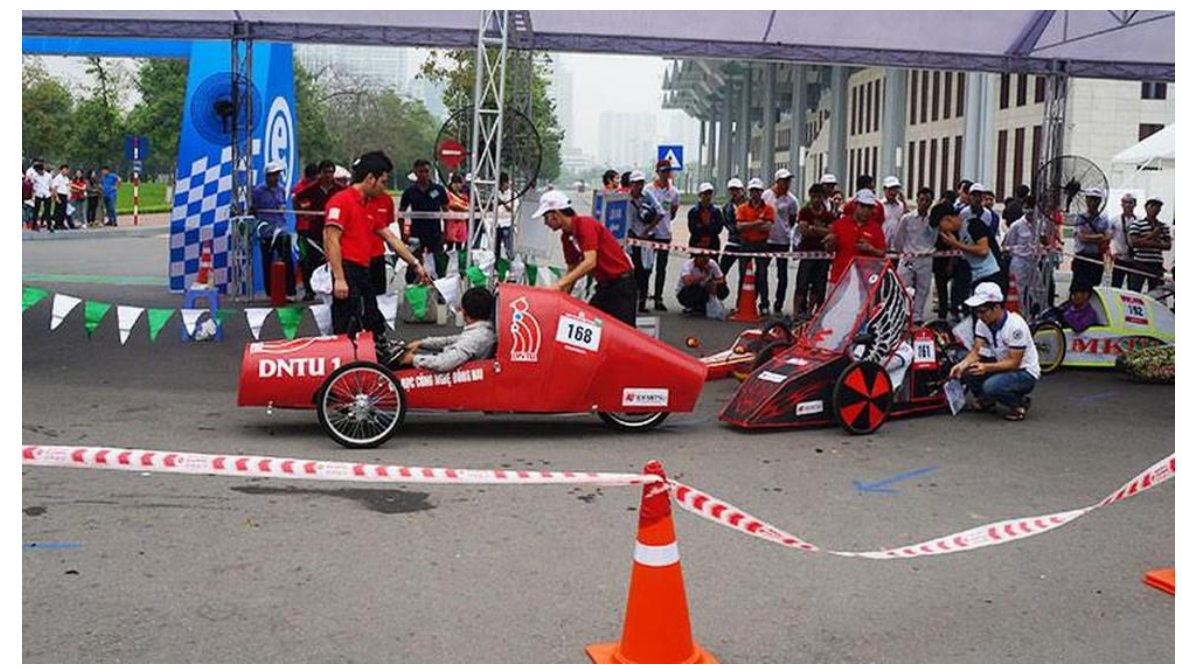

Hình 4. Các sinh viên tham gia thi đấu

\section{Phương pháp đánh giá}

Sau khi thiết kế hoàn chỉnh một cơ cấu, một hệ thống trên mô hình. Giảng viên sẽ có những câu hỏi vấn đáp, xoáy sâu vào kiến thức của sinh viên và sinh viên phải trình bày được tại sao phải thiết kế như vậy. Qua đó, giúp giảng viên đánh giá được năng lực của sinh viên theo cách chủ quan và khách quan. Kết quả đánh giá cho thấy hầu hết các sinh viên với phương pháp này và sinh viên thể hiện được khả năng xử lí tình huống, giải quyết vấn đề.

\section{Kết luận}

Nghiên cứu đã sử dụng một dự án có một số yêu cầu đáp ứng theo thực tế cho sinh viên thực hiện. Sau khi hoàn thành, sinh viên được đánh giá khả năng thiết kế, sáng tạo của mình bằng cách tham gia cuộc thi. Qua đó sinh viên có thể nhận biết được những ưu và nhược điểm của sản phẩm mình tạo ra. Kết quả cho thấy, sinh viên rất hào hứng với phương pháp dạy theo dự án dựa trên CDIO. Dự án được thực hiện thành công, sinh viên đáp ứng đủ yêu cầu về kiến thức và kĩ năng.

\section{Tài liệu tham khảo}

[1] Hồ Tấn Nhựt, Đoàn Thị Minh Trinh (Biên dịch), 2009, "Cải cách và xây dưng chuoong trình đào tạo kỹ thuật theo phuoong pháp tiếp cận CDIO”, Nxb Đại học Quốc gia TP.HCM.

[2] Nguyễn Thành Hải, Phùng Thúy Phượng, Đồng Thị Bích Thủy, 2010. "Giới thiệu một số phuơng pháp giảng dạy cải tiến giúp sinh viên học tập chủ động và trải nghiệm, đạt các chuẩn đầu ra theo CDIO", Hội thảo CDIO 2010_Đại học Quốc Gia Tp.HCM.

[3] Nguyễn Thành Hải, 2010, "Phưong pháp học tập chủ động ở bậc đại học", Trung tâm nghiên cứu cải tiến phương pháp dạy và học đại học, Trường ĐH Khoa Học TựNhiên - ĐH Quốc Gia TP. HCM.

[4] Trần Kim Hương, "Bản đồ tu duy_Phuoong pháp dạy và học hiệu quả", Khoa Sư phạm Toán_Tin, Trường ĐH Đồng Tháp. 
